\title{
IMPROVEMENT OF THE METHODOLOGY FOR ASSESSING DOMESTIC WASTEWATER TREATMENT QUALITY USING BENCHMARKING TOOLS
}

\author{
IRINA RUKAVISHNIKOVA ${ }^{1}$, ANDREY KISELEV $^{1,2}$, MARIA BEREZYUK $^{1} \&$ IULIA ASHIROVA $^{1}$ \\ ${ }^{1}$ Ural Federal University, Russia \\ ${ }^{2}$ Vodokanal, Ekaterinburg, Russia
}

\begin{abstract}
Problems with the treatment efficiency of domestic wastewater for the Ural Federal district have remained relevant for several decades. More than $55 \%$ of the total amount of contaminated wastewater originates from municipal wastewater utilities. Sectoral legislation reform, the development of private capital and tariff regulation have contributed to the long-term improvement of municipal wastewater utilities in solving modernization and environmental problems, including the involvement of different groups of stakeholders in this process. The existing methods and tools for assessing the achievements of key performance indicators in the field of domestic wastewater treatment are not representative, do not reflect the dynamic results; information turnover occurs with no publicity; and there is no possibility to compare results with similar companies in other districts of the Russian Federation, to identify and replicate the best practices. This paper proposes a methodical approach for wastewater treatment quality assessment conducted by water companies. The transition from the currently used indicator, the proportion of sewage samples that do not meet the accepted standards for allowable discharge standards (ADS), doesn't allow making an adequate assessment of the water companies' efforts in wastewater treatment facilities' modernization, towards indicators that take into account the multiplicity and frequency of ADS excess by effluent components, is suggested. The proposed indicators can be used in sectoral benchmarking, for assessment of the effectiveness of the environmental activities within wastewater utilities. The comparison and analysis of the indicators' dynamics can help identify and replicate the best practices used in the field of wastewater treatment processing, under conditions of availability of information to the professional community. Finally, this action will create significant progress for water companies on the issue of reducing negative environmental impacts.
\end{abstract}

Keywords: benchmarking, quality assessment, Russia, sustainable development, wastewater treatment, water quality, water treatment.

\section{INTRODUCTION}

The Water Strategy of the Russian Federation [1] presupposes the adoption and implementation of management decisions for the conservation of aquatic ecosystems and the creation of conditions for the effective interaction of participants in water relations.

The main components of the water management complex in the Russian Federation are water utilities or water supply and sewage organizations (WSS). They draw water from surface and/or underground sources of water supply, and they provide water treatment and transportation of water to the consumer, as well as wastewater and sewage treatment. Effective operation of WSS utilities reduces the negative impact on water bodies by improving the quality of wastewater treatment and conservation of natural ecosystems.

In the Russian Federation, the amount of discharged contaminated sewage produced by the housing and communal services enterprises, primarily water utilities, is $>60 \%$ of the total volume of discharged contaminated sewage. The reasons for this are the considerable wear and tear of the treatment facilities, the use of obsolete wastewater treatment technologies, and the discharge of contaminated sewage by industrial companies [1]. 
Along with the problem of the negative impact on water bodies, most enterprises of the WSS industry have a wide range of problems to solve, the most significant of which are: a high degree of depreciation of pipes and infrastructure, and as the result, a large number of accidents; significant water losses and wastewater spill into the soil; and insufficient quality of the drinking water supplied to the citizens. One more problem for municipal enterprises is insufficient funding of the WSS utilities.

Modern trends in the field of economics and management within the sphere of water supply and sewage, as well as in other spheres of the communal sector, are: a market approach to pricing; the transition to a format of concession legislation; and the involvement of stakeholders interested in the results of company activities. The success of these processes is directly related to the open, reliable and complete provision of information on various aspects of the enterprises' activities. The global professional community helps to successfully realize it with the help of the institute of public non-financial reporting [2].

An effective tool for optimizing the activities of enterprises is benchmarking, which involves comparison of a company's performance with the benchmark indicators of enterprises-industry leaders; and an analysis of the dynamics of the company's performance [3], [4]; besides, it is very important to have a valid approach to the formation of a system of benchmarking indicators.

This article gives an analysis of the current state of the problem of assessing the effectiveness of water utilities, the effectiveness of company management. The emphasis is on improving the methodological approach to assessing the company's efforts to reduce the impact on water bodies. The research object is the municipal unitary enterprise (MUE) 'Vodokanal' that provides the water supply and water disposal in the city of Ekaterinburg, in the Sverdlovsk region of the Russian Federation.

\section{THE PROBLEM OF RESERVOIR POLLUTION BY SEWAGE IN THE SVERDLOVSK REGION OF THE RUSSIAN FEDERATION}

The effectiveness of wastewater treatment for the Ural Federal District has remained an urgent problem for several decades. Sewage discharge into surface water bodies in 2016 amounted to 816.83 million $\mathrm{m}^{3}$, of which the discharge of contaminated sewage is 616.60 million $\mathrm{m}^{3}$, accounting for $75 \%$ of the total discharge [5]. At the same time, the discharge of contaminated sewage in the whole Russian Federation was $34.2 \%$ of the total discharge [6].

The discharge of contaminated sewage is the main source of pollution of water bodies in the Sverdlovsk region [5]. The greatest amount of contaminated wastewater enters surface water bodies from enterprises working in the spheres of: communal services, 55\%; processing industries, $30 \%$; and mineral extraction, $9 \%$.

The contribution to wastewater disposal in surface water bodies in 2016 of the main types of economic activity is presented in Fig. 1.

MUE 'Vodokanal' in Ekaterinburg is one of the most significant sources of surface water pollution in the Sverdlovsk Region of the Russian Federation. According to the state's statistical reporting of the enterprise, although it has a very significant amount of discharge, almost all the discharged wastewater is not sufficiently purified (Fig. 2).

Perhaps such a high percentage of insufficiently treated sewage slightly exaggerates the actual extent of the water company's impact on water bodies and is related to the specifics of the current approach of the Russian Federation's government to the regulation of discharge from enterprises operating within a municipal sewer range.

The fact is that for the last 25 years in Russia, the discharge of purified wastewater from water utilities is subject to high requirements, which are determined by the maximum 


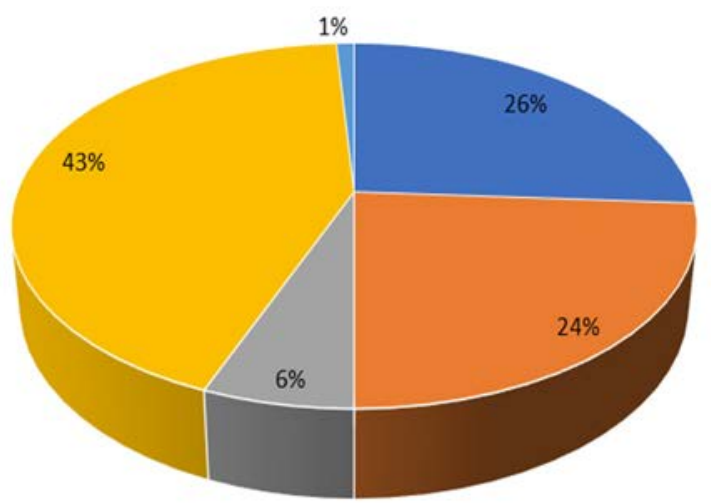

" extraction of minerals

" processing industries

" production and distribution of electricity, gas and water

" other communal social and personal services, disposal of sewage and waste, other activities of the kind

- other kinds of economic activity

Figure 1: Contribution to wastewater disposal in surface water bodies in 2016 of the main activities, million cubic metres $\left(\mathrm{m}^{3}\right)$.

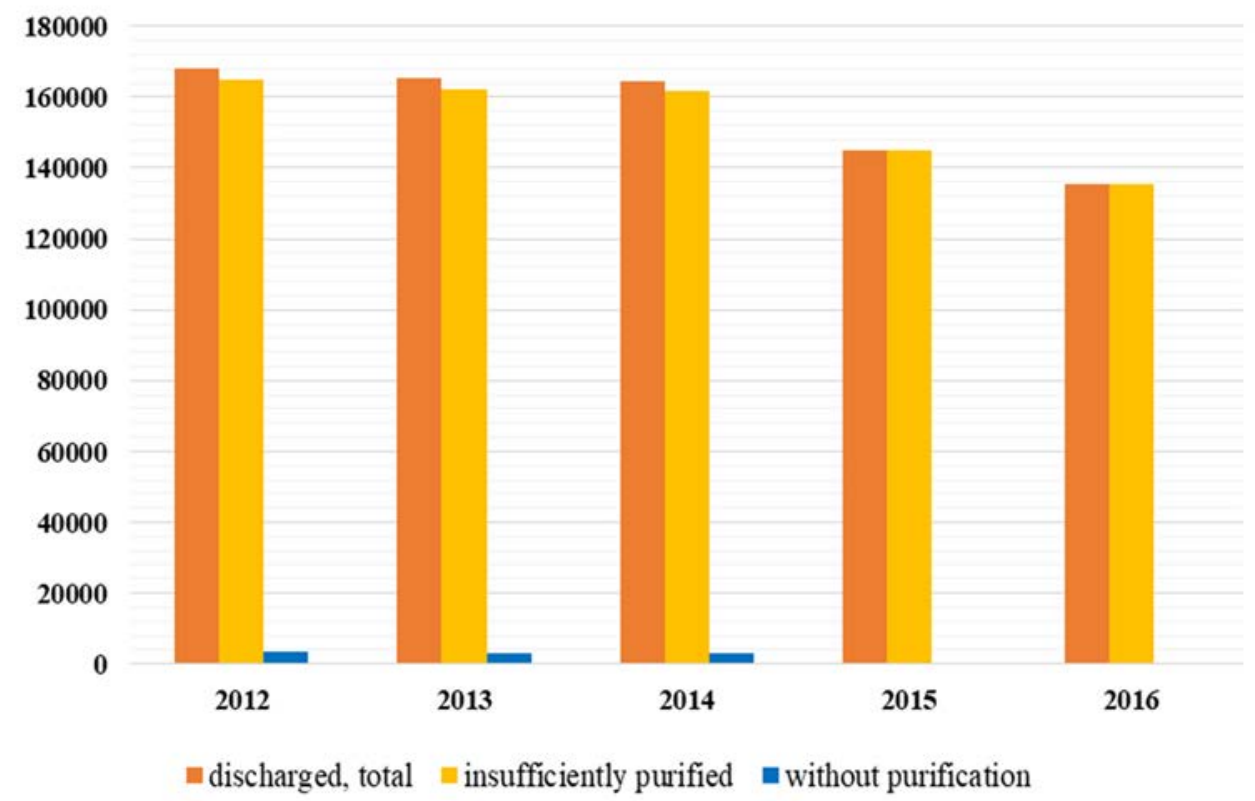

Figure 2: Dynamics of sewage discharge of Municipal Unitary Enterprise 'Vodokanal' in millions of $\mathrm{m}^{3}$. 
permissible concentrations (MPC) of harmful substances at the level of standards established for water as object of fishery usage. Most of these standards are technically incorrect in relation to domestic wastewater.

During the whole period of existence of such an approach, the sectoral and expert community asked for its revision and they succeeded. Starting in 2019, the order of wastewater discharge standardization will change dramatically: there will be a transition from the standardization of pollutant discharges based on water quality standards for water bodies of importance to fisheries, to the regulation based on the best available technologies (BAT) [7]. This approach has been successfully applied in EU countries [8], [9], based on the fact that it is possible to demand the achievement of only those values of environmental impact indicators that are steadily demonstrated on at least a few of the best facilities in the industry. All necessary information for the implementation of technological regulation is contained in the information and technical reference book ITRB 10-2015 'Wastewater Treatment using Municipal and Urban districts' Sewerage,' approved in 2015 [10].

Apparently, the reform of the regulation of discharges will significantly affect the quantitative indicator of the volume of insufficiently treated sewage; and will change the existing approach to assessing the effectiveness of the water companies, in terms of impact on water bodies.

\section{CURRENT APPROACH TO THE EVALUATION OF THE EFFICIENCY OF WATER FACILITIES}

At present, to evaluate the performance of water facilities we use indicators of reliability, quality and energy efficiency, enlisted and approved by the Order of the Ministry of Construction Industry, Housing and Utilities Sector of the Russian Federation (RF Ministry of Construction): No. 162, April 4, 2014. The activities of the water utilities and the effectiveness of their management are evaluated by the stakeholders to achieve such targets. If indicators are not reached, then sanctions are imposed; for example the required gross revenue decreases through tariff formation (which may lead to a reduction in tariffs).

The indicators of reliability, quality and energy efficiency include, among other things, quality indicators for wastewater treatment. The list of indicators that determine the quality of wastewater treatment includes:

1. The proportion of untreated wastewater in the total amount of wastewater (for domestic and drainage sewage);

2. The proportion of sewage samples that do not meet the accepted standards for the allowable discharge rate (ADR) and discharge limits.

The informative nature of the first indicator is beyond doubt. As for the second indicator, questions arise.

As already mentioned above, the allowable discharge standards (ADS) for water companies are currently established on the basis of water quality standards for water bodies of importance to fisheries, which are much more stringent than the norms for a potable water supply. The treatment facilities of most water companies cannot provide the required degree of purification for a number of substances. In particular, there are no special methods for domestic wastewater treatment from the so-called technogenic pollution: heavy metals, petroleum products, surfactants (synthetic surface-active substances), etc. [7]. As a result, despite all the efforts of water utilities (implementation of new technologies, modernization of facilities), the concentration of a number of substances in the samples always exceeds the concentration corresponding to ADS, i.e. the indicator 'the share of sewage samples that do not meet the established standards for permissible discharges (ADS) is always 100\%'. 
This indicator does not allow adequate assessment of the efforts of water utilities to improve the quality of wastewater treatment and to compare the results of purification in dynamics, compare with the results of other water utilities and ultimately, stimulate the reduction of the negative impact of the enterprise on water bodies. To solve these problems, it is necessary to use other indicators of the quality of wastewater treatment.

\section{EVALUATION OF THE QUALITY OF WASTEWATER TREATMENT OF A}

WATER UTILITY FACILITY: MUNICIPAL UNIT ENTERPRISE 'VODOKANAL'

Wastewater treatment at the water facility of Ekaterinburg takes place at the Northern Aeration Station (NAS), the Southern Aeration Station (SAS) and wastewater treatment facilities in the village of Severka (WTF Severka).

The NAS is among the most modern, technically equipped wastewater utilities in Russia; however, even the plants exceed in the concentrations of a number of substances on each sample, corresponding to the ADS. According to the enterprise's reporting for the years 2014 to 2016, the concentration of phosphates in the samples exceeded the ADS in $100 \%$ of the cases, while the mass of soluble zinc compounds is $97 \%$. We face $>50 \%$ the excess of ADS of BOD (20), ammonium nitrogen. Thus, in accordance with the current methodology of the Ministry of Construction of the Russian Federation, the treated sewage samples do not correspond to the established ADS in $100 \%$ of the cases.

The problem may be solved by replacing the quality indicator of sewage treatment with 'the share of sewage samples that do not correspond to the established ADS' by the indicator 'the share of unsatisfactory indicators in sewage samples' $\left(D_{u n}\right)$. To determine this indicator, it is necessary to fix the proportion of components that exceed the ADS for each sample, and then to determine the average percentage of unsatisfactory indicators in the samples for the reporting period. This indicator can be calculated in accordance with eqn (1):

$$
D_{u n}=\frac{\sum_{i=1}^{n} \frac{n_{u n_{i}}}{n_{i}}}{n},
$$

where $n=$ total number of samples for the reporting period;

$n_{u n_{i}}=$ number of unsatisfactory indicators in the $i$-sample; and

$n_{i}=$ number of indicators in the $i$-sample.

This indicator, being simple and intuitive, can be used to inform the public about the impact of the enterprise on water bodies. It should be noted that the indicator shows the dynamics of the quality of wastewater treatment but does not take into account the impact of pollutants on water bodies and the frequency of excess of ADS for particular substances.

Fig. 3 shows the 3-year dynamics of the number of stably unsatisfactory indicators and substances, the average mass of which is several times higher than the ADS in the total number of samples.

Histograms show only those substances/masses that exceed ADS in $>40 \%$ of the cases taken into account. The proportion of substances, the mass of which virtually exceeds ADS in all samples (80-90\% of the total number of samples), is shown separately.

From our point of view, the repeatability (frequency) of ADS excess and the repetition factor of ADS excess by individual substances can themselves be used as indicators of the quality of wastewater treatment. Presented on the histogram, they clearly reflect the most critical indicators of purification and determine the priority optimization measures; however, 
0.5

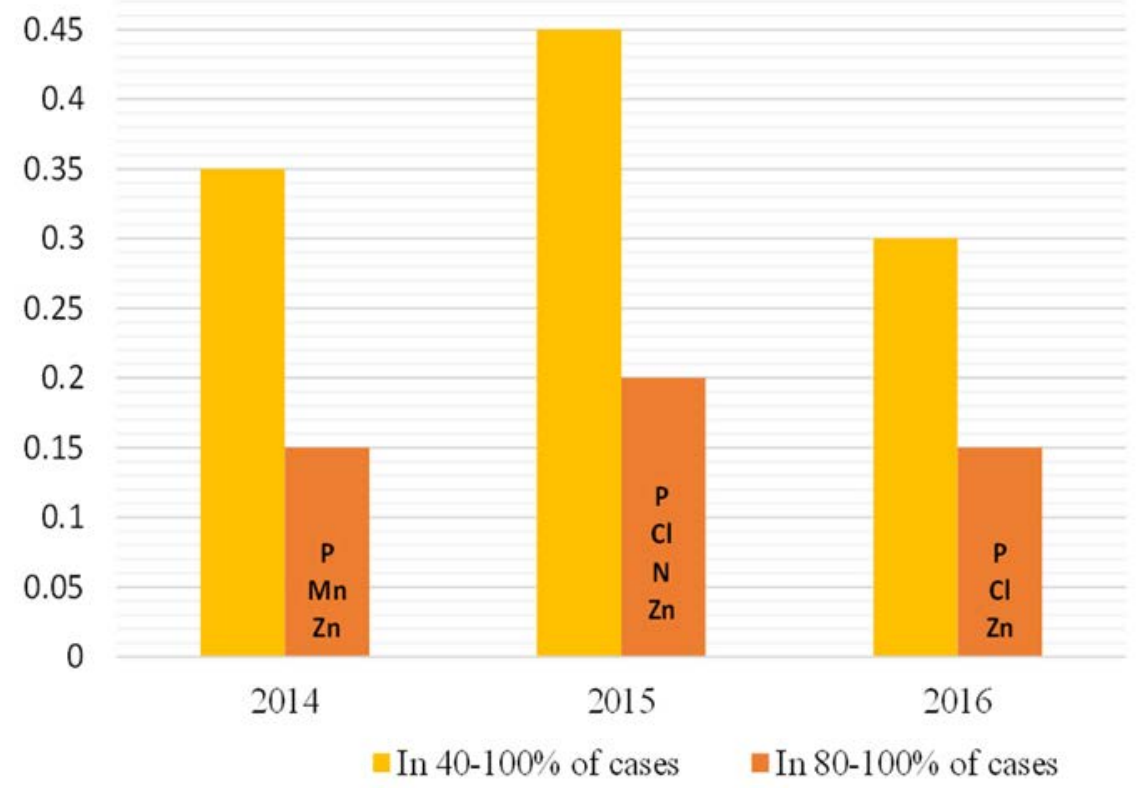

0.16

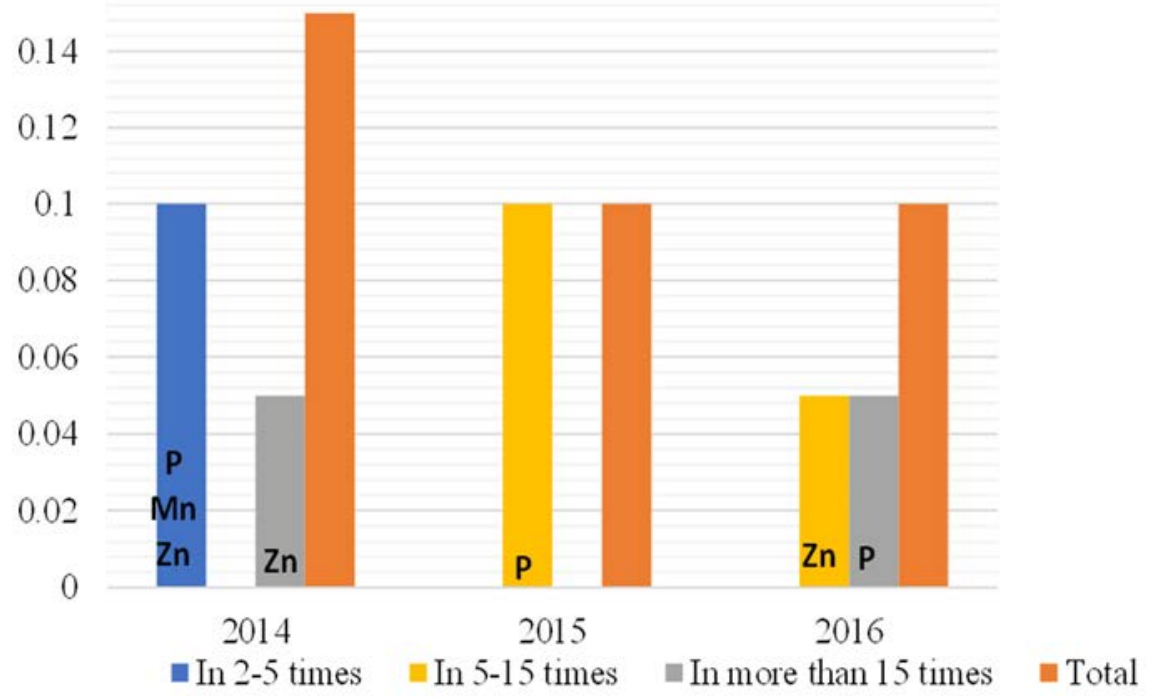

Figure 3: Shares of the total number of indicators of SAS sewage components with high repeatability of ADS: (a) and with a high multiplicity of ADS; (b) with $\mathrm{P}-$ $\mathrm{P}\left(\mathrm{PO}_{4}{ }^{3-}\right), \mathrm{Mn}-\mathrm{Mn}$ (sol.), $\mathrm{Zn}-\mathrm{Zn}$ (sol.), $\mathrm{Cl}-\mathrm{Cl}\left(\mathrm{Cl}^{-}\right)$, and $\mathrm{N}-\mathrm{N}\left(\mathrm{NH}_{4}{ }^{+}\right)$. $\mathrm{ADS}=$ Allowable Discharge Standards; $\mathrm{Cl}=$ chlorine; $\mathrm{N}=$ nitrogen; $\mathrm{P}=$ phosphorous; $\mathrm{Zn}=$ zinc. 
it is advisable to combine both parameters in the integral coefficient to provide more complete information in a condensed form, especially to provide information to professional and expert communities. For this purpose, it is possible to use the approach first applied in 1998 by Vasilyeva et al. [11]; it would help to form a combinatorial index of water pollution.

To calculate this index, it is necessary to determine for each ingredient: the multiplicity of ADS excess, which is the ratio of the average actual concentration to ADS and the rating score of multiplicity $\left(K_{i}\right)$; and repeatability (frequency) of cases of ADS excess, which is the ratio of cases exceeding the total number of measurements and the estimated repeatability rating point $\left(H_{i}\right)$.

On the basis of certain points, it is possible to calculate the total estimated score of sewage contamination by the $i$-component, as a product of multiplicity and repeatability scores. The sum of $B_{i}$ can be used as a combined indicator of wastewater treatment quality (CIWTQ), which can be calculated according to eqn (2):

$$
\text { CIWTQ }=\sum_{i=1}^{n} B_{i}=\sum_{i=1}^{n} K_{i} \mathrm{H}_{i} .
$$

In accordance with Vasilyeva et al. [11], the repeatability score Hi of the excess is calculated as the result of linear interpolation (Table 1) for different ranges of values for the frequency of ADS excess.

To estimate the multiplicity of excess, we propose using a coefficient of the intensity of negative exposure of harmful substances (pollutants) on the water body. This coefficient was enlisted in the method of calculating the damages caused to water facilities [12] and used in Russia from the year 2009. It depends on the multiplicity of times exceeding the actual concentration of harmful substances (pollutants) upon the release of resetting sewage, drainage water above its concentration, in waters of the water facilities. This coefficient can be used as the initial multiplicity evaluating score $(K i)$.

For harmful substances of Class I and II hazard, the coefficient of intensity of the negative impact (multiplicity evaluating score) is taken as being equal to the calculated multiplicity excess.

The estimated scores for the excess of ADS for hazardous substances of Classes III and IV, corresponding to the negative impact intensity coefficients [12], are given in Table 2.

Table 3 compares the combined quality indices of wastewater treatment computed by us for three groups of water treatment facilities in Ekaterinburg, for 2 years (unfortunately, we do not have available data on the average actual concentration of pollutants for 2016). At the treatment facilities in the village of Severka, the concentrations of only 11 components are evaluated in the samples (the concentrations of water-soluble metal compounds are not estimated). Therefore, Table 3 gives combinatorial indices for 11 sample components, for all treatment facilities, and 20 samples from Northern and Southern aeration stations.

The Table 3 results can be used to compare the effectiveness of wastewater treatment in three treatment plant complexes, monitoring the dynamics of the quality of cleaning at each

Table 1: Estimated scores for different frequency ranges.

\begin{tabular}{|c|c|}
\hline Frequency & Estimated score for frequency \\
\hline$(1 ; 10)$ & $(1,2)$ \\
\hline$(10 ; 30)$ & $(2,3)$ \\
\hline$(30 ; 50)$ & $(3,4)$ \\
\hline$(50 ; 100)$ & 4 \\
\hline
\end{tabular}


Table 2: Estimated scores for the excess of allowable discharge rate concentration for Class III and IV hazardous substances.

\begin{tabular}{|c|c|}
\hline Multiplicity of ADR excess & Estimated score for multiplicity of excess \\
\hline up to 10 & 1 \\
\hline from 10 to 50 & 2 \\
\hline more than 50 & 5 \\
\hline
\end{tabular}

ADR: allowable discharge rate.

Table 3: Combined index of quality of wastewater treatment for treatment facilities of MUE 'Vodokanal', Ekaterinburg, Russia.

\begin{tabular}{|l|c|c|c|c|}
\hline \multirow{2}{*}{ Treatment facilities } & \multicolumn{2}{|c|}{2014} & \multicolumn{2}{c|}{2015} \\
\cline { 2 - 5 } & 20 & 11 & 20 & 11 \\
\hline NAS & 34 & 23 & 36 & 28 \\
\hline SAS & 43 & 31 & 36 & 32 \\
\hline WTF 'Severka' & - & 39 & - & 31 \\
\hline
\end{tabular}

MUE: municipal enterprise unit, NAS: Northern Aeration Station, SAS: Southern Aeration Station, WTF: wastewater treatment facility.

aeration station. Of course, to complete the picture and analyze its dynamics, it would be good to be able to compare the indices in a few more years.

From our point of view, the combined index could be used as one of the indicators for benchmarking, which makes it possible to compare the effectiveness of wastewater treatment at the water companies in the Russian Federation. A set of purification quality indicators, including a combined index and repeat histograms and multiplicity of ADS excess, could provide a fairly complete picture of the quality of wastewater treatment at the country's water management complex enterprises.

\section{BENCHMARKING AS A TOOL FOR ASSESSING AND IMPROVING THE EFFICIENCY OF WATER UTILITIES}

It is important that the results of the activity of the water facilities can be easily accessible by representatives of the professional community and the general public. The mechanism to inform proposed by the current Standards of Information Disclosure in the field of water supply and sanitation does not fully provide a solution to this problem. Data provided by organizations are collected by specialized agencies; disclosure of information on environmental problems and actions takes place only if there is an initiative taken by a water and sewer enterprise. In Russia, information on the activities of water utilities is not concentrated in a single, easily accessible information source. We believe that the use of public, non-financial reporting and benchmarking tools for the distribution and analysis of information can have a big effect on the development of water utilities, and on ensuring environmental safety [13].

Benchmarking (or reference comparison, in other words) implies systematic activity aimed at finding, evaluating and using the best business practices. It allows identification both of the strengths of an enterprise, and any weakness which needs to be improved. It also helps to find innovative solutions for the company.

Under conditions of low competition in the communal sector, the systemic use of benchmarking can form a system of indicators that will stimulate utilities to continuously 
improve their efficiency in various activities, and to improve the quality of services provided to the population.

Benchmarking is successfully used on a long-term basis by the water facility located in Saint Petersburg, Russia [14]. This enterprise is a recognized industry leader, striving to make full use of the best world practices for optimizing all areas of its activities [15]. The enterprise uses both external and internal benchmarking. External benchmarking involves finding innovative solutions and best practices of domestic and foreign enterprises in the industry, internal benchmarking involves comparing the effectiveness of the enterprise's business units, by sharing best practices [14].

Vodokanal of St. Petersburg has been participating in the International Benchmarking Program since 2014. This program is organized and held annually by the European Organization of Benchmarking (EBO) [16]. The Foundation provides a unified framework for data collection, with a methodology that is based on the recommendations of the International Water Association (IWA) [17], made in accordance with the calculation of key indicators. This makes it possible to ensure that the indicators considered are comparable. Participation in the international benchmarking program is undoubtedly a positive experience that can be recommended to all the other water facilities in Russia.

The American Water Works Association (AWWA) [18] successfully implements a similar benchmarking program. The basis of the AWWA benchmarking system is also a specially developed indicator system. It consists of 22 separate indicators and control points collected into five groups, each of which is responsible for a certain direction of activity of participant water management enterprises.

The Indicator 'Efficiency of Sewage Treatment' is included in the group of indicators of the main processes of water supply and wastewater. It is an indicator of the compliance of the wastewater that is discharged after treatment, according to the required standards. We think that in Russia, the function of this indicator can be performed by a combined indicator of quality of wastewater treatment.

Despite the long-running harmonization processes, Russian standards for wastewater treatment quality differ significantly from European and American ones. Therefore, the current task is the development of a system of indicators, convertible over time into international systems. St. Petersburg's Vodokanal formulates a very promising proposal to create a Russian benchmarking program for water utilities, which can be headed by the Expert Council of the Russian Association of Water Supply and Sanitation (RAWSS).

\section{CONCLUSION}

The tasks to develop management solutions that maximally contribute to the modernization of treatment facilities, to provide the greatest effect for improving the state of water bodies is very important, especially under conditions of uncompensated negative impact of water sector enterprises on the water environment, which is currently strained as a result of the ecological situation. Systematic and professional use of industry benchmarking could become one of such solutions. Moreover, when an unlimited number of people disclose information on the results and dynamics of non-financial performance indicators, including the quality of wastewater treatment, there should be an additional incentive force aimed at improving the efficiency of water treatment facilities.

Successful usage of sectoral benchmarking and public non-financial reporting is in the development of a justified indicator system for directing the main company activities.

The methodical approach proposed within this paper assumes the usage of the following wastewater treatment quality indicators: 
1. The share of unsatisfactory indicators in sewage samples (instead of the "proportion of sewage samples that do not meet the accepted standards for allowable discharge rate (ADR) and discharge limits" that is now used by water companies);

2. The share of sample components with high repeatability of exceeding allowable discharge standards (ADS) and with a high multiplicity of exceeding ADS;

3. The combined indicator of wastewater treatment quality, which takes into account the repeatability and multiplicity of exceeding ADS by the main pollutants, at the same time.

From the authors' point of view, the proposed indicators can be used for sectoral benchmarking of water companies' environmental protection activities within the Russian Federation, as well as for internal benchmarking within a water companies' departments. It is very important that water companies' wastewater treatment quality indicators, along with other key performance indicators, should be available to the general public, including the professional community and the company's stakeholders.

Regular benchmarking will allow water companies to evaluate their wastewater treatment efficiency in a dynamic way, and to identify and replicate the best practices of advanced enterprises. It is expected that the environment have negative impact reduction and improved habitat conditions as the most significant results.

\section{ACKNOWLEDGEMENT}

This work was supported by Act 211 of the government of the Russian Federation, contract No. 2.A 03.21.0006.

\section{REFERENCES}

[1] Water Strategy of the Russian Federation until 2020, The Russian Federation government decree of August 27, 2009.

[2] Hawrysz, L. \& Maj, J., Identification of stakeholders of public interest organisations. Sustainability, 9(1609), pp. 1-13, 2017.

[3] Bonson, E. \& Bednarova, M., CSR reporting practices of Eurozone companies. Revista de Contabilidad - Spanish Accounting Review, 18(2), pp. 182-193, 2015.

[4] Mustapha, M., Manan, Z. \& Alwi, S., A new quantitative overall environmental performance indicator for a wastewater treatment plant. Journal of Cleaner Production, 167, pp. 815-823, 2017.

[5] On the State and Environmental Protection of the Russian Federation in 2016, state report. www.mnr.gov.ru/regulatory/list.php?part=2118. Accessed on: 20 Jan. 2018.

[6] On the Condition and Environment Protection in the Sverdlovsk Region in 2016, state report. http://mprso.midural.ru/uploads/ekologiya-pravki-2009--gotovo.pdf. Accessed on: 20 Jan. 2018.

[7] Danilovich, D., In review: a change in rationing the dischargers of water utilities and their clients. Ecology of Production, 1, pp. 10-18, 2018.

[8] Garcia Quesada, M., The EU as an "enforcement patchwork": the impact of national enforcement for compliance with EU water law in Spain and Britain. Journal of Public Policy, 34(2), pp. 207-227, 2014.

[9] Fuerhacker, M., The water framework directive - can we reach the target? Water Science and Technology, 57(1), pp. 9-17, 2008.

[10] Information and Technical Reference Book ITRB 10-2015 "Waste Water Treatment Using Centralized Drainage Systems for Settlement and Urban Districts". http://docs.cntd.ru/document/1200128670. Accessed on: 20 Jan. 2018.

[11] Vasilyeva, E.A. et al., How to Organize Public Environmental Monitoring, SoES: Moscow, 1998. 
[12] Method of calculating the amount of damage caused to water bodies due to violation of water legislation, 2009. http://base.garant.ru/12167365/. Accessed on: 20 Jan. 2018.

[13] Ilysheva, N.N. \& Kiselev, A.V., Public non-financial reporting improvement of water supply and sewerage enterprises for sustainable and safety spatial development. Economics and Management: Problems and Solutions, 3(68), pp. 90-95, 2017.

[14] Karmazinov, F.V., Benchmarking is an effective instrument for the development of enterprises of the country's water industry. Best Available Technologies for Water Supply and Sanitation, 3, pp. 18-23, 2016.

[15] Rukavishnikova, I., Strukova, M., Strukova, L., Karaeva, A. \& Gabova, I., Introduction of ISO management systems in municipal enterprises providing water supply, water preparation and wastewater treatment in the major cities of the Russian Federation. Journal of Sustainable Development and Planning, 1(12), pp. 71-78, 2017.

[16] European Organization of Benchmarking, www.waterbenchmark.org. Accessed on: 20 Jan. 2018.

[17] International Water Association, http://iwanet.org/. Accessed on: 20 Jan. 2018.

[18] American Water Works Association, www.awwa.org. Accessed on: 20 Jan. 2018. 